\title{
EFICIÊNCIA DE TELAS TERMOREFLETORAS E DE SOMBREAMENTO EM AMBIENTE PROTEGIDO TIPO TELADO SOB TEMPERATURAS ELEVADAS
}

\author{
Renato Rampazzo ${ }^{1}$, Santino Seabra Junior ${ }^{2}$, Maria Cândida Moitinho Nunes ${ }^{3}$, Sandra Mara Alves da Silva Neves ${ }^{4}$, \\ Regiane Fátima Ferreira ${ }^{5}$
}

\begin{abstract}
RESUMO
O cultivo em ambiente protegido permite a realização de cultivos em épocas que normalmente não seriam apropriadas para a produção em campo aberto. Objetivou-se com este trabalho avaliar as variações de luminosidade, temperatura do ar e do solo e umidade relativa do ar, em diferentes ambientes de cultivo, no período seco e no chuvoso, em Cáceres-MT, utilizando telados com malhas de 30, 40 e 50\% de sombreamento, telas termorefletoras com 30, 40 e 50\% de sombreamento e uma área de campo aberto. O delineamento experimental utilizado foi o de blocos casualizados com 10 repetições, representadas por 10 dias de coleta. Foi observado que os ambientes telados reduziram os valores mínimos, médios e máximos dos atributos luminosidade e temperatura do ar e proporcionaram aumento na umidade relativa do ar, quando comparados com o ambiente campo aberto. Os telados com tela de sombreamento de 40 e $50 \%$ e tela termorefletora 50\% apresentaram maior eficiência para a redução da luminosidade e da temperatura do ar. A tela de sombreamento $50 \%$ foi a que proporcionou maiores índices de umidade relativa do ar entre os tratamentos.
\end{abstract}

Palavras-chave: condições climáticas, cultivo protegido, épocas de cultivo, horticultura tropical

\section{ABSTRACT \\ EFFICIENCY OF TERMO-REFLECTIVE SCREENS AND SHADING IN PROTECTED ENVIRONMENTAL SUBMITTED TO HIGH TEMPERATURES}

Cultivation in protected environments allows for crop production in seasons that normally would not be suitable for open field production. This study sought to evaluate the variations in luminosity, air and soil temperature and relative humidity of the air in different environmental conditions during the winter and summer, in Cáceres-MT, using screens with mesh of 30, 40 and 50\% shading, thermo-reflective screens with 30, 40 and 50\% shading and an open field. The experimental design utilized consisted of randomized blocks with 10 replications, represented by 10 days of collection. It was observed that the screened environments reduced the minimum, average and maximum values of the luminosity and air temperature attributes, and resulted in an increase in relative humidity compared to the open field environment. The black screens with $40 \%$ and 50\% shading and the 50\% thermo-reflective screen presented greatest efficiency to reduce luminosity and air temperature. The screen with $50 \%$ shading was that which resulted in the greatest indices of relative humidity of the air among the treatments.

Keywords: climatic conditions, growing seasons, protected cultivation, tropical horticulture

Recebido para publicação em 06/06/2012. Aprovado em 04/12/2013.

1 - Engenheiro Agrônomo, UNEMAT. E-mail: renato_rampazzo@hotmail.com

2 - Engenheiro Agrônomo, Dr. Prof. Adjunto, Departamento de Agronomia, UNEMAT. E-mail: santinoseabra@hotmail.com

3 - Engenheira Agrícola, Dr. Prof. Adjunto, Departamento de Solos, UFPEL. E-mail: nunes.candida@gmail.com

4 - Geógrafa, Dr. Prof. Adjunta, Departamento de Geografia, UNEMAT. E-mail: ssneves_geo@hotmail.com

5 - Eng. Agrônomo, Prof. E.E. Jayme Veríssimo de Campos Jr., Alta Floresta-MT; E-mail: ane_fat@hotmail.com 


\section{INTRODUÇ̃̃O}

O cultivo em ambiente protegido no Brasil não é recente, há registros de trabalhos no final dos anos 60, no entanto, no final dos anos 80 e, principalmente, no início da década de 90 é que esta técnica de produção passou a ser amplamente utilizada (SILVA et al., 2011). O cultivo em ambiente protegido, além de ser eficaz no controle parcial das condições edafoclimáticas, também permite a realização de cultivos em épocas que normalmente não seriam apropriadas para a produção ao ar livre. Nesse sistema, as plantas efetuam o uso mais eficiente da água e, desta forma, reduzem a necessidade hídrica. Outro fator preponderante para a produção em ambiente protegido é o melhor aproveitamento dos recursos essenciais para a produção (nutrientes, luz solar e $\mathrm{CO}_{2}$ ), o que reduz o uso de insumos, como fertilizantes (fertirrigação) e defensivos (PURQUERIO; TIVELLI, 2006), incorrendo em redução de custos e, consequentemente, maior lucratividade ao produtor.

As modificações climáticas que ocorrem em cada tipo de ambiente protegido dependem do tipo de cobertura empregada. Estufa, túnel, agrotêxtil e malhas de sombreamento têm sido muito utilizadas como proteção de cultivo. Dentre estas, a mais conhecida é o telado (branco, preto, aluminizado), que pode apresentar porcentagens variáveis de absorção e bloqueio de luminosidade.

Os telados pretos, denominados telas de sombreamento, têm por objetivo amenizar problemas relacionados à irradiância e temperatura elevadas, condições características de regiões tropicais, contribuindo para um bom desenvolvimento das hortaliças, aumentando a sua produção e viabilizando seu cultivo ao longo do ano (DIAMANTE et al., 2013).

As telas de sombreamento pretas reduzem a incidência direta dos raios solares nas espécies que necessitam de menor fluxo de energia radiante, consequentemente, reduzindo a temperatura. A menor incidência de energia solar pode contribuir para diminuir os efeitos extremos da radiação, principalmente a fotorrespiração, e proporcionar melhores condições ambientais, aumentando a produtividade e qualidade das folhas para consumo (MACIEL et al., 2009). Contudo, o uso dessas telas pode representar uma redução no fluxo de luz a níveis inadequados, promovendo prolongamento do ciclo, estiolamento das plantas e redução da produtividade. Outra forma de se conduzir a produção de culturas, principalmente hortaliças, com condições ambientais controladas é a utilização das telas termorrefletoras (telado aluminizado) e difusoras, devido ao fato de sua composição proporcionar mais luz difusa ao ambiente, promovendo redução da temperatura, todavia não afetando significativamente os processos relacionados à fotossíntese (LEITE, 2010).

Para a produção de alface, além da incidência de radiação solar, a temperatura do ar é de suma importância, pois é um fator agrometeorológico que exerce grande influência sobre as funções vitais das plantas como a germinação, transpiração, respiração, fotossíntese, crescimento, floração e frutificação. Para as condições climáticas brasileiras, consideradas tropicais e subtropicais, onde o cultivo de hortaliças é possível durante o ano todo, o aquecimento natural demasiado do ambiente pode causar problemas no cultivo das plantas (PURQUERIO; TIVELLI, 2006). Teltela et al. (1995) avaliaram a temperatura do ar sob 5 tipos de telados ( $20 \%$ branco, 30,40 e $50 \%$ preto e $50 \%$ aluminizado) em Israel e concluíram que telas de sombreamento estendidas horizontalmente sobre a cultura podem reduzir os danos causados por geadas e que as telas termorefletoras são mais efetivas na redução da temperatura do ar. Segundo os autores, essas malhas fornecem $15 \%$ de radiação difusa ao ambiente e não interferem nos processos fotossintéticos.

Outro fator impactante na produção de hortaliças folhosas em ambiente protegido é a temperatura do solo, sendo esta de grande significância ecológica para a vida vegetal, influenciando mais no desempenho da planta que a temperatura do ar. Para Goto e Tivelli (1998), a temperatura do solo é muito influenciada pela cobertura que ele apresenta, sempre havendo diferença entre a temperatura do solo no interior e no exterior do ambiente protegido.

A umidade relativa está intimamente atrelada ao equilíbrio hídrico das plantas, onde um déficit pode 
alterar a evapotranspiração das plantas e o excesso pode acarretar desordens fisiológicas devendo essa ser mantida em níveis adequados (PURQUERIO; TIVELLI, 2006). No interior do ambiente protegido a umidade relativa e a temperatura do ar apresentam seus valores inversamente proporcionais e variáveis, ou seja, com o aumento da temperatura, a umidade relativa diminui no interior do ambiente, tornandose igual ou inferior à umidade externa (GUISELINE; SENTELHAS, 2004).

No município de Cáceres-MT, os produtores vêm apresentando baixa produtividade e problemas com qualidade da alface e outras hortaliças folhosas, tanto em ambiente protegido quanto em campo aberto. Dessa forma, mostra-se necessário fazer uma avaliação das condições climáticas que ocorrem dentro desses ambientes, analisando os dados de temperatura do ar, umidade relativa do ar e luminosidade. Para as condições climáticas de Cáceres-MT, não existem trabalhos nesta área e os resultados obtidos podem ser úteis para determinar qual dos ambientes melhor responde às necessidades da cultura, possibilitando assim que o produtor local possa manter sua produção durante todo o ano. Dessa forma, este estudo objetiva-se em avaliar a eficiência de telas termorefletoras e de telas de sombreamento em parâmetros ambientais, sob condições de temperaturas elevadas.

\section{MATERIAL E MÉTODOS}

O experimento foi conduzido na área experimental pertencente à Universidade do Estado de Mato Grosso - UNEMAT, localizada no município de Cáceres-MT. A altitude média do local é de 118 metros, latitude de $16^{\circ} 04^{\prime} 33^{\prime \prime}$ sul e longitude de $57^{\circ} 39^{\prime} 10^{\prime \prime}$ oeste. A região apresenta clima Tropical (Aw), com temperatura média do mês mais frio superior a $18{ }^{\circ} \mathrm{C}$, inverno seco e verão chuvoso. A temperatura média anual é de $26,24{ }^{\circ} \mathrm{C}$. A temperatura média mensal mais alta ocorre no mês de outubro $\left(28,01^{\circ} \mathrm{C}\right)$ e as médias mensais mais baixas nos meses de junho e julho, 23,39 e $23,36{ }^{\circ} \mathrm{C}$, respectivamente. A precipitação total anual é de $1.335 \mathrm{~mm}$ (NEVES et al., 2011).

As coletas de dados dos parâmetros ambientais foram realizadas em local sob cultivo de alface (Lactuca sativa). A condução do experimento foi realizada em esquema fatorial $2 \times 7$, sendo duas épocas de cultivo (Verão e Inverno) x sete ambientes de cultivo (campo aberto, telas de sombreamento 30,40 e $50 \%$ e tela termorefletora 30,40 e $50 \%$ ), dispostos em delineamento experimental de blocos casualizados, com 10 repetições (sendo considerado cada dia de coleta como uma repetição).

Os ambientes apresentam dimensões de 10 x 10 $\mathrm{m}$. Em cada ambiente foram preparados 5 canteiros, com 0,2 $\mathrm{m}$ de altura, $9 \mathrm{~m}$ de comprimento e $1,5 \mathrm{~m}$ de largura cada, com espaçamento entre estes de 0,3 m. Cada ambiente ocupa uma área de $100 \mathrm{~m}^{2}$, com pé direito 2,4 $\mathrm{m}$ de altura (Figura 1).

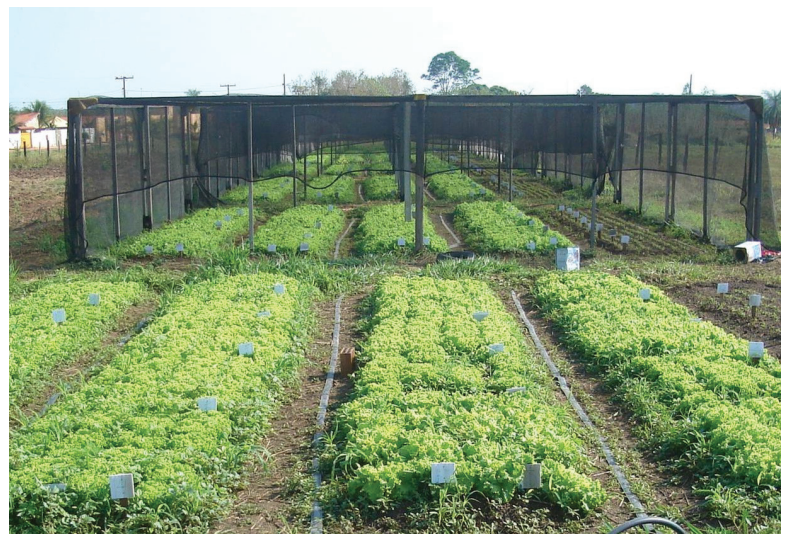

Figura 1. Vista parcial do ambiente telado e do campo aberto cultivado com alface.

O solo predominante na área de estudo é classificado como Plintossolo Pétrico Concrecionário distrófico (EMBRAPA, 2006), composto por $617 \mathrm{~g} \mathrm{~kg}^{-1}$ de areia, $145 \mathrm{~g} \mathrm{~kg}^{-1} \mathrm{de}$ silte e $337 \mathrm{~g} \mathrm{~kg}^{-1}$ de argila. Este solo apresenta os seguintes atributos químicos: $\mathrm{MO}=4,0 \mathrm{~g} \mathrm{dm}^{-3} ; \mathrm{pH}$ $=4,6 ; \mathrm{P}=3,37 \mathrm{mg} \mathrm{dm}^{-3} ; \mathrm{K}=0,08 \mathrm{cmol}_{\mathrm{c}} \mathrm{dm}^{-3} ; \mathrm{Ca}=$ $0,6 \mathrm{cmol}_{\mathrm{c}} \mathrm{dm}^{-3} ; \mathrm{Mg}=0,4 \mathrm{cmol}_{\mathrm{c}} \mathrm{dm}^{-3} ; \mathrm{Al}=0,3 \mathrm{cmol}_{\mathrm{c}}$ $\mathrm{dm}^{-3} ; \mathrm{CTC}=3,68 ; \mathrm{V}=29 \%$.

Foram coletados, de forma manual, dados de temperatura do ar, temperatura do solo, umidade relativa do ar e luminosidade. As coletas foram realizadas 3 vezes ao dia, às 7,13 e $18 \mathrm{~h}$, num período de 30 dias, representando o ciclo da planta após o transplante, sendo que, destes 30 dias de coleta, foram utilizados 10 dias de coleta escolhidos ao acaso para confecção da estatística. Os horários das coletas foram escolhidos em função da representatividade de variação da temperatura ao longo do dia. 
Para a coleta da temperatura do solo foram utilizados termômetros portáteis, modelo TEC1311, sendo estes introduzidos no solo a uma profundidade de $0,10 \mathrm{~m}$. Esse procedimento foi repetido nos 7 ambientes avaliados, nos 5 canteiros que compunham cada ambiente e três vezes ao dia $(7,13$ e $18 \mathrm{~h})$ e seus dados expressos em graus Celsius $\left({ }^{\circ} \mathrm{C}\right)$. Para a obtenção dos dados de temperatura do ar e de umidade relativa do ar, foram utilizados Termo-Higrômetro, modelo HT-208, protegidos da incidência direta de luminosidade e dispostos ao mesmo tempo nos 7 ambientes, na altura padrão de coleta de dados em estações meteorológicas, ou seja, a 1,5 m da superfície do solo. As coletas partiram do ambiente campo aberto até o último ambiente coberto, tela termorefletora $50 \%$. Em cada ambiente as coletas foram repetidas três vezes, no intervalo de 5 minutos e três vezes ao dia, às 7,13 e $18 \mathrm{~h}$.

Para mensurar as características relacionadas à luminosidade foi utilizado um luxímetro. Foram realizadas três coletas por canteiro, nos cinco canteiros presentes em cada ambiente, nos sete ambientes avaliados e três vezes ao dia, às 7, 13 e $15 \mathrm{~h}$.

$\mathrm{O}$ experimento foi realizado em dois períodos, chuvoso (dezembro de 2008) e seco (julho de
2009), sendo que todos os procedimentos utilizados foram iguais para os dois períodos de cultivo. Para determinação das médias da temperatura do ar, temperatura do solo, umidade relativa média do ar e luminosidade nos três horários de coleta, foi utilizada a média aritmética simples.

Para a análise estatística foram estipulados como valores mínimos as coletas efetuadas às 7 $\mathrm{h}$ e para valores máximos as coletas às $13 \mathrm{~h}$. Os valores médios foram obtidos por meio de médias simples entre os valores máximos e mínimos. As médias obtidas foram submetidas à análise de variância e comparadas pelo teste de Tukey a 5\% de probabilidade, por meio do programa Estat 2.0 (KRONKA; BANZATO, 1995).

\section{RESULTADOS E DISCUSSÃO}

Foi verificado que não houve interação significativa entre as épocas de coleta e os tipos de ambientes (telados e campo aberto) e, desta forma, os dados foram discutidos separadamente. Em relação às épocas de cultivo, pode-se observar no Quadro 1 que, para todas as variáveis avaliadas, houve diferença entre as médias encontradas, exceto para luminosidade máxima, onde não foi

Quadro 1. Umidade relativa mínima do ar (URMI), média do ar (URME) e máxima do ar (URMA), luminosidade mínima (LMI), média (LME) e máxima (LMA), sob Campo Aberto (CA), Tela de sombreamento 30\% (S30\%), 40\% (S40\%) e 50\% (S50\%), Tela termorefletora 30\% (TR30\%), $40 \%(\mathrm{TR} 40 \%)$ e $50 \%$ (TR $50 \%)$

\begin{tabular}{|c|c|c|c|c|c|c|}
\hline \multirow{2}{*}{ Época } & URMI & URME & URMA & LMI & LME & LMA \\
\hline & \multicolumn{3}{|c|}{----------- (\% ) ------------ } & \multicolumn{3}{|c|}{ (LUX) -------------- } \\
\hline Chuva & $60,74 \mathrm{a}$ & $63,63 \mathrm{a}$ & $66,46 \mathrm{a}$ & $18.99 \mathrm{a}$ & $35.910 \mathrm{a}$ & $52.575 \mathrm{a}$ \\
\hline Seca & $35,07 \mathrm{~b}$ & $39,10 \mathrm{~b}$ & $43,12 b$ & $14.51 \mathrm{~b}$ & $33.347 \mathrm{~b}$ & $52.127 \mathrm{a}$ \\
\hline
\end{tabular}

Ambiente

\begin{tabular}{lllllll}
$\mathrm{CA}$ & $43,81 \mathrm{~b}$ & $47,48 \mathrm{~b}$ & $51,11 \mathrm{~b}$ & $25,64 \mathrm{a}$ & $56,92 \mathrm{a}$ & $86,31 \mathrm{a}$ \\
$\mathrm{S} 30 \%$ & $48,25 \mathrm{ab}$ & $52,69 \mathrm{a}$ & $57,08 \mathrm{a}$ & $14,52 \mathrm{c}$ & $34,34 \mathrm{bc}$ & $54,34 \mathrm{bc}$ \\
$\mathrm{S} 40 \%$ & $47,18 \mathrm{ab}$ & $51,01 \mathrm{a}$ & $54,77 \mathrm{ab}$ & $11,93 \mathrm{c}$ & $26,85 \mathrm{~d}$ & $42,58 \mathrm{~cd}$ \\
$\mathrm{~S} 50 \%$ & $49,45 \mathrm{a}$ & $52,78 \mathrm{a}$ & $56,07 \mathrm{a}$ & $13,62 \mathrm{c}$ & $27,66 \mathrm{~d}$ & $41,71 \mathrm{~d}$ \\
$\mathrm{TR} 30 \%$ & $47,40 \mathrm{ab}$ & $51,28 \mathrm{a}$ & $55,12 \mathrm{ab}$ & $21,54 \mathrm{ab}$ & $39,80 \mathrm{~b}$ & $58,04 \mathrm{~b}$ \\
$\mathrm{TR} 40 \%$ & $50,64 \mathrm{a}$ & $52,80 \mathrm{a}$ & $54,91 \mathrm{ab}$ & $15,95 \mathrm{bc}$ & $30,27 \mathrm{~cd}$ & $44,40 \mathrm{~cd}$ \\
$\mathrm{TR} 50 \%$ & $48,59 \mathrm{ab}$ & $51,56 \mathrm{a}$ & $54,49 \mathrm{ab}$ & $14,05 \mathrm{c}$ & $26,56 \mathrm{~d}$ & $39,08 \mathrm{~d}$ \\
$\mathrm{CV}(\%)$ & & & & & & \\
\hline
\end{tabular}

* Médias seguidas pela mesma letra nas colunas não diferem entre si pelo teste Tukey, a 5\% de probabilidade. 
encontrada diferença significativa ente as médias do período chuvoso e do seco.

Como era esperado, com relação à umidade relativa do ar, foi observada diferença entre os cultivos do período de chuva e de seca, sendo que o período maior pluviosidade (dezembro) apresentou maior umidade relativa máxima, média e mínima do ar.

Em relação à umidade relativa do ar, nenhum dos ambientes proporciona valores adequados, pois segundo Sganzerla (1997), os dados obtidos estão fora dos padrões mínimos para a cultura (Quadro 1), podendo, desta forma, comprometer o desenvolvimento da cultura e sua produção. Dessa forma, o uso de um sistema de microaspersão suspenso dentro do ambiente protegido poderia, durante os horários de menor umidade relativa, aumentar a umidade relativa do ar.

A umidade relativa do ar no interior de um ambiente protegido possui uma relação inversamente proporcional à temperatura. Ela pode variar num período de $24 \mathrm{~h}$, de 30 a $100 \%$, sendo que diminui durante o dia e aumenta durante a noite, essa variação também pode estar atrelada às irrigações efetuadas durante o cultivo e às médias de precipitação que cada local de cultivo apresenta. Ela está vinculada ao equilíbrio hídrico das plantas, onde um déficit pode alterar a evapotranspiração, alterando a capacidade do sistema radicular de absorver a água e os nutrientes (PURQUEIRO; TIVELLI, 2005).

Foram observados valores médios de umidade relativa do ar em ambiente protegido superiores aos obtidos em campo aberto. Tal diferença está associada ao efeito protetor do ambiente protegido que atua de forma a reter maior quantidade de vapor d'água em seu interior. Outro fato a considerar é o fenômeno da advecção lateral que tende a transferir vapor d'água para outras áreas e contribuir para o aumento do fluxo de calor sensível, fenômeno este mais comum em condição de campo. Em termos médios, a umidade relativa do ar, medida em condição de ambiente protegido, foi 5,1\% superior à obtida em campo aberto, com 52,69 e 47,48\%, respectivamente.

Para o parâmetro luminosidade média, as coberturas se portaram de forma similar ao parâmetro luminosidade mínima. $\mathrm{O}$ único tratamento que se portou de forma diferente foi a tela de sombreamento $30 \%$, que apresentou maior incidência de luminosidade entre os ambientes protegidos, ficando atrás apenas tratamento campo aberto, que como era de se esperar apresentou as maiores médias de incidência de luminosidade. Para a luminosidade máxima, os tratamentos podem ser divididos em quatro grupos, pelo grau de significância a $5 \%$ de probabilidade. Sendo o primeiro onde não teve bloqueio de luminosidade, o campo aberto; no segundo grupo estariam as telas de sombreamento $30 \%$ e tela termorefletora $30 \%$ com aproximadamente $35 \%$ de bloqueio da luminosidade, o terceiro grupo a tela de sombreamento $40 \%$ e a tela termorefletora $40 \%$, apresentando bloqueio de $50 \%$ da luminosidade máxima; e por último as telas que apresentaram maior eficiência no bloqueio de luminosidade máxima, com $64 \%$ de bloqueio da luminosidade.

Gotto e Tivelli (1998) afirmam que para culturas sensíveis ao excesso de luminosidade, o uso de telas de sombreamento, com 30 a $50 \%$ de sombra, soluciona satisfatoriamente o problema de luminosidade, e a modificação da luminosidade no ambiente interfere nos demais fatores ambientais. Com relação à luminosidade mínima, observamos que os ambientes cobertos com tela de sombreamento juntamente com tela termorefletora $50 \%$ foram os que receberam menor incidência de luminosidade e não apresentaram diferença entre si estatisticamente.

As telas termorefletoras com 30, 40 e $50 \%$ de sombreamento apresentaram uma redução da luminosidade de $33,60,46,81$ e $53,33 \%$, respectivamente. Levando em consideração a tela de sombreamento houve a redução da luminosidade média, onde as malhas de 30,40 e $50 \%$ bloqueiam em torno de 36-39, 40-44 e 50-55\% para tela de sombreamento 30,40 e $50 \%$, respectivamente, bloquearam $39,67,52,83$ e $51,40 \%$ de luz, respectivamente.

Em relação às variáveis luminosidade, temperatura do ar e temperatura do solo, pode-se observar que durante o período do verão foram verificadas as maiores incidências das variáveis em questão. Verifica-se também que os parâmetros temperatura do ar e do solo são amplamente influenciados pela luminosidade. Isto ocorre porque 
o verão apresenta maior incidência de radiação solar e, consequentemente, maior luminosidade, o que faz com que as temperaturas sejam maiores do que as observadas no inverno.

Para as variáveis temperatura média e máxima do ar, a maioria dos tratamentos proporcionou um ambiente com temperatura do ar acima da tolerável por diversas plantas (Quadro 2). Para a alface, por exemplo, segundo Filgueira (1981), a temperatura máxima tolerável é de $30{ }^{\circ} \mathrm{C}$. Nessas condições experimentais foram registradas temperaturas do ar superiores a $27{ }^{\circ} \mathrm{C}$ para todas as variáveis. Segundo Wien (1997), a temperatura média ideal para o crescimento da alface é de $18{ }^{\circ} \mathrm{C}$. Já para Sganzerla (1997), as temperaturas ótimas para o desenvolvimento adequado da alface é de 14 a 18 ${ }^{\circ} \mathrm{C}$ durante o dia e de 5 a $20{ }^{\circ} \mathrm{C}$ durante a noite, devendo estes valores estarem conjugados com umidade relativa do ar entre 60 e $70 \%$.

Foi observada uma tendência de aumento de temperatura e diminuição da umidade, já que os valores de temperatura e umidade relativa são inversos. Esse fenômeno fica evidente no experimento pelas maiores temperaturas do ambiente campo aberto em relação aos demais ambientes e em relação à umidade relativa do ar, que apresenta menores valores que os demais ambientes, corroborando com os resultados de Purqueiro e Tivelli (2005).

Por meio do melhoramento genético têm sido desenvolvidas cultivares mais tolerantes às altas temperaturas e ao fotoperíodo longo, ou seja, adaptados às condições tropicais e sub-tropicais, sem estimular o pendoamento e o sabor amargo das folhas. A técnica do cultivo protegido, aliada ao melhoramento genético que permitiu o surgimento de cultivares adaptadas às condições tropicais, proporcionou o aumento da produção dessa folhosa, possibilitando a oferta do produto nos períodos de entressafra (CRUZ, 2005).

Os ambientes que apresentaram maior incidência luminosa apresentaram diferenças na variável temperatura mínima do ar. Este foi o caso do ambiente campo aberto, tela de sombreamento $30 \%$ e tela termorefletora $30 \%$, que apresentaram maior incidência de radiação solar, fazendo com que a temperatura mínima do ar fosse maior. Não houve diferença significativa entre as temperaturas médias

Quadro 2. Temperatura mínima do ar (TAMI), média do ar (TAME) e máxima do ar (TAMA), temperatura mínima do solo (TSMI), média do solo (TSME) e máxima do solo (TSMA), em diferentes épocas de cultivo, sob Campo Aberto (CA), Tela de sombreamento 30\% (S30\%), 40\%(S40\%) e $50 \%$ (S50\%), Tela termorefletora 30\% (TR30\%), 40\% (TR40\%) e 50\% (TR50\%).

\begin{tabular}{|c|c|c|c|c|c|c|}
\hline Énoca & TAMI & TAME & TAMA & TSMI & TSME & TSMA \\
\hline Verão & $30,15 \mathrm{a}$ & $31,96 \mathrm{a}$ & $33,71 \mathrm{a}$ & $28,42 \mathrm{a}$ & $30,19 \mathrm{a}$ & $32,00 \mathrm{a}$ \\
\hline Inverno & $26,90 \mathrm{~b}$ & $29,56 \mathrm{~b}$ & $32,22 \mathrm{~b}$ & $21,32 \mathrm{~b}$ & $24,04 \mathrm{~b}$ & $26,75 \mathrm{~b}$ \\
\hline \multicolumn{7}{|c|}{ Ambiente } \\
\hline $\mathrm{CA}$ & 30,17 a & $33,49 \mathrm{a}$ & 36,79 a & $25,40 \mathrm{a}$ & $28,13 \mathrm{a}$ & 30,88 a \\
\hline S30\% & $28,26 \mathrm{ab}$ & $30,64 \mathrm{~b}$ & $32,70 \mathrm{~b}$ & $24,54 \mathrm{a}$ & $27,00 \mathrm{ab}$ & $29,46 \mathrm{ab}$ \\
\hline $\mathrm{S} 40 \%$ & $27,83 \mathrm{~b}$ & $29,89 \mathrm{~b}$ & $31,94 \mathrm{~b}$ & $24,65 \mathrm{a}$ & $26,61 \mathrm{~b}$ & $28,58 \mathrm{~b}$ \\
\hline $\mathrm{S} 50 \%$ & $27,74 \mathrm{~b}$ & $29,83 \mathrm{~b}$ & $32,05 \mathrm{~b}$ & $24,56 \mathrm{a}$ & $26,80 \mathrm{~b}$ & $29,05 \mathrm{~b}$ \\
\hline TR30\% & $28,71 \mathrm{ab}$ & $30,55 \mathrm{~b}$ & $32,38 \mathrm{~b}$ & $25,21 \mathrm{a}$ & $27,49 a b$ & $29,81 \mathrm{ab}$ \\
\hline TR40\% & $28,44 \mathrm{ab}$ & $30,40 \mathrm{~b}$ & $32,35 \mathrm{~b}$ & $24,99 \mathrm{a}$ & $27,05 \mathrm{ab}$ & $29,15 \mathrm{~b}$ \\
\hline TR50\% & $28,22 \mathrm{~b}$ & $30,42 \mathrm{~b}$ & $32,55 \mathrm{~b}$ & $24,76 \mathrm{a}$ & $26,73 \mathrm{~b}$ & $28,73 \mathrm{~b}$ \\
\hline CV (\%) & 6,56 & 7,09 & 8,58 & 4,86 & 4,54 & 5,67 \\
\hline
\end{tabular}

* Médias seguidas pela mesma letra nas colunas não diferem entre si pelo teste Tukey a 5\% de probabilidade 
e máximas entre os telados, contrariando os dados de Leite (2009) que afirma que a radiação que entra no sistema influencia na temperatura do ar.

Levando em consideração as temperaturas mínimas no interior dos ambientes protegidos, quando comparadas as do ambiente externo, não houve diferenças significativas para os tratamentos tela de sombreamento $30 \%$ e tela termorefletora 30 e $40 \%$, isso evidencia a pouca eficiência dessas malhas de sombreamento em proporcionar uma diminuição na temperatura mínima ambiente, o que também foi obtido por Sousa et al. (2005).

Quando se considera apenas os ambientes protegidos, observa-se que não há diferença significativa entre os tratamentos. Estes resultados diferem dos encontrados por Semedo (1988) e Braga (2000) que utilizaram telas termorefletoras e afirmam que a temperatura máxima é influenciada pelo tipo de cobertura. Com base nos resultados encontrados neste experimento afirmamos que a escolha do material para a confecção do ambiente protegido não deve ter como característica primordial a temperatura do ar, já que não diferem entre si, tendo desta forma que basear-se em preços ou outras características que apresentem diferenças significativas e tragam maior custo-benefício aos produtores. Para redução da temperatura mínima do ar, os tratamentos que se mostraram mais eficientes foram os com cobertura tipo tela de sombreamento 40 e $50 \%$ e tela termorefletora $50 \%$, com diminuição da temperatura mínima do ar de 2,43; 2,34 e 1,95 ${ }^{\circ} \mathrm{C}$, respectivamente (Quadro 1).

Para a variável temperatura do solo, com relação à temperatura mínima, não houve diferença significativa entre os tratamentos utilizados o que, segundo Galvani et al. (2000), pode estar relacionado com a formação de um dossel homogêneo da cobertura vegetal.

Ao comparar a redução da temperatura média do ar nos telados, em relação ao campo aberto (Quadro 2), foi verificado que a percentagem de redução de temperatura média do ar foi de $9,56 \%$, inferior à descrita por Aburre et al. (2003), os quais apresentam a possibilidade de redução de 10 a $20 \%$ na temperatura do ar.

Para as variáveis temperatura média e máxima do solo, os tratamentos com tela de sombreamento 40 e $50 \%$ e tela termorefletora $50 \%$ foram os que apresentaram menores temperaturas. Este resultado indica que quanto maior o percentual de sombreamento das telas, menor a temperatura do solo. Estes resultados são contrários aos obtidos por Leite (2009), o qual menciona que a tela de sombreamento tem como objetivo acumular e separar calor, isto é, ocorre um intercâmbio entre o ar que fica retido na tela e a radiação emitida que é absorvida por elementos refrigerados abaixo do telado, como o solo e as plantas. Segundo o autor, a malha de alumínio não esquenta em absoluto, pois é refletora. Desta forma, pode-se questionar a eficiência da tela termorefletora, já que não diferencia significativamente das telas de sombreamento. Purqueiro e Tivelli (2005) destacam que a melhor maneira para se conseguir uma faixa ótima de temperatura do solo é utilizando irrigação. No verão, se o manejo da temperatura do ar e da irrigação for bem realizado, utilizando ambientes protegidos e métodos de irrigação adequados, podem contribuir para a manutenção da faixa ideal para cada cultura. Um fator que pode contribuir para a amenização da temperatura do solo é a cobertura com material orgânico existente sobre os canteiros. Segundo Acosta et al. (2004), o acúmulo de material orgânico na superfície do solo ameniza, principalmente, a temperatura máxima encontrada no solo nos períodos mais quentes do dia, proporcionando condições mais estáveis de temperatura para o crescimento vegetal.

Isto se confirma pelos dados de temperatura média do ar e do solo e luminosidade média (Quadro 1), uma vez que, para as três características avaliadas, os ambientes tela de sombreamento 40 e $50 \%$ e tela termorefletora $50 \%$ se equivalem, apresentando os menores valores nos parâmetros avaliados. Mazuchoeski et al. (2007), em análise das temperaturas do solo nas profundidades de 5 e $10 \mathrm{~cm}$, trabalhando com três diferentes telas de sombreamento $(70,50$ e $30 \%$ de efeito redutor da luminosidade), observaram diferenças marcantes nos dados, destacando a importância do sombreamento, pois quanto maior o grau de sombreamento, maior foi a redução de luminosidade e menor a temperatura do solo, variando do horário matinal ao vespertino, quando atinge os ápices diários. Neste trabalho, entretanto, quando se compara a tela de sombreamento 40 e $50 \%$ com a tela termorefletora 
$50 \%$, não se observa a diferença significativa, tanto para a temperatura média do solo quanto para temperatura máxima. Para temperatura máxima do solo foi verificada a mesma tendência observada para temperatura média, ou seja, os ambientes mais eficientes para redução da temperatura média, tela de sombreamento 40 e $50 \%$ e tela termorefletora $50 \%$, foram os mais eficientes também para a temperatura máxima do solo.

A redução da temperatura do ar e do solo é benéfica às brássicas e asteráces cultivadas em condições tropicais. A redução da temperatura do ar pode trazer benefícios como diminuir o volume transpiratório, evitando uma redução comprometedora do conteúdo líquido da folha, o que pode causar uma foto-oxidação, causando morte de células (RYDER, 1999) e até mesmo um acúmulo de látex nas folhas e um pendoamento precoce em alface e rúcula (FILGUEIRA, 2000). Para essa redução, todas as telas utilizadas foram eficientes, porém, existe uma grande diferença de preço entre estas, podendo chegar a $70 \%$ quando comparado à tela de sombreamento com a tela termorefletora. Estes materiais apresentaram um aumento significativo no custo de implantação dos ambientes protegidos tipo telado, porém é apresentado pelo fabricante que as telas termorefletoras apresentam uma durabilidade maior que a da tela de sombreamento, além da tela termorefletora obter ganhos satisfatórios em produtividade, podendo esses, se bem manejados, chegar a 40\%. Este ganho está relacionado com a passagem de luz sem calor em forma de luz difusa, diminuindo a temperatura por ser revestida de alumínio (LEITE, 2009).

\section{CONCLUSÕES}

- O comportamento dos parâmetros climáticos nos diferentes ambientes não variou quando comparadas as épocas de coletas (chuva e seca);

- O cultivo em ambiente protegido tipo telado foi eficiente na redução da temperatura do ar e do solo e da luminosidade, além de propiciar um aumento na umidade relativa do ar, indicando ser viável o uso destes materiais para cultivo em condições tropicais;
- As telas de sombreamento 40 e $50 \%$ apresentaram maior eficiência na redução dos parâmetros ambientais, justificando o uso dessas para o município de Cáceres, pela sua eficiência e menor custo $(30 \%)$ em relação à termorefletora.

\section{REFERÊNCIAS BIBLIOGRÁFICAS}

ABAURRE, M.E.O.; PUIATTI, M.; CECON, P.R.; COELHO, M.B.; HUAMAN, C.A.M.Y.; PEREIRA, F.H.F.; AQUINO, L.A. Produtividade de duas cultivares de alface sob malhas termorefletoras e difusa no cultivo de verão. Horticultura Brasileira. v.21, n.2, 2003.

ACOSTA, J.A.A.; GIRARDELLO, V.; WEBER, M.A.; ROSSATO, O.B.; SANTI, O.G.R.; LOVATO, T.; AMADO, T.J.C. Efeito na temperatura e na umidade do solo pelo aporte de resíduos orgânicos de culturas de cobertura. In: VIII INIC e IV EPG, 2004, São José dos Campos. VIII INIC e IV EPG. Resumos... São Paulo, p.1515-1518. 2004.

ANDRIOLO, J.L. Fisiologia das culturas protegidas. Santa Maria: Editora da UFSM, 1999. 142 p.

BRAGA, M.B. Manejo da irrigação e orientação geográfica de estufas na produção do pimentão (Capsicim annuum L.). 2000. 89p. Dissertação (Mestrado em Energia na Agricultura) - Faculdade de Ciências Agronômicas, Universidade Estadual Paulista, Julio Mesquita Filho, Botucatu, 2000.

BEZERRA, F.C. Produção de mudas de hortaliças em ambiente protegido. Fortaleza; Embrapa Agroindústria Tropical, 2003. 22p, Documentos, 72 .

CRUZ, C.D. Princípios de genética quantitativa. Viçosa: UFV. 2005, 394p.

DIAMANTE, M.S.; SEABRA JÚNIOR， S.; INAGAKI, A.M.; SILVA, M.B.; DALLACORT, R. Produção e resistência ao pendoamento de alfaces tipo lisa cultivadas sob diferentes ambientes. 
Revista de Ciências Agronômicas, n.1, p.133$140,2013$.

EMBRAPA. Centro Nacional e Pesquisa de Solos. Sistema Brasileiro de Classificação de Solos. 2 ed. Brasília: Embrapa Produção de Informação; Rio de Janeiro: Embrapa Solos, 306p, 2006.

FILGUEIRAF.A.R. Novo manual de olericultura. Agrotecnologia moderna na produção e comercialização de hortaliças. Viçosa: UFV, 2000. 402p.

FILGUEIRA, F.R. Manual de olericultura: cultura e comercialização de hortaliças. 2. ed., São Paulo :Ed. Agronômica Ceres, 1981. v.1, 338p.

GALVANI, E; ESCOBEDO, J.F.; PEREIRA, A.B. Balanço de radiação e fluxo de calor no solo em ambiente natural e protegido cultivado com pepineiro. Bragantia [online]. 2001, v.60, n.2, p.139-147. ISSN 0006-8705.

GOTO, R.; TIVELLI, S.W. Produção de hortaliças em ambiente protegido: condições subtropicais. In: TIVELLI, S.W. Manejo do ambiente em cultivo protegido. São Paulo: UNESP, 1998. 319p.

GRANDE, L.; LUZ, J.M.Q.; MELO, B.; LANA, R.M.Q.; CARVALHO, J.O.M. O cultivo protegido de hortaliças em Uberlândia-MG. Horticultura Brasileira, Brasília, v.21, n.2, p.241-244, 2003.

GUISELINI C.; SENTELHAS P.C. Uso de malhas de sombreamento em ambiente protegido I: Efeito na temperatura e na umidade do ar. Revista Brasileira de Agrometeorologia, Santa Maria, v.12, n.1, p.9-17, 2004.

KIRDA, C.; ÇEVIK, B.; TÜLÜCÜ, K. A simple method to estimate the irrigation water requirement of greenhouse grown tomato. Acta Horticulturae, Wageningen, v.1, n.59, p.373-80, 1994.

KRONKA, S.N.; BANZATO, D.A. Estat: sistema para análise estatística. versão 2.0. 3ed. Jaboticabal: FUNEP, 1995. 247p.
MACIEL, S.P.A; ZANELLA, F.; LIMA, A.L.S. Efeito do sombreamento sobre a produção de alface em hidroponia. Disponível em: $<\mathrm{http}: / /$ docs.google.com/gview? $\mathrm{a}=\mathrm{v} \& \mathrm{q}=$ cache: 1 menR9O RI6EJ:www.revista.ulbrajp.edu.br/seer/inicia/ojs/ include/getdoc.php $\% 3$ Fid\%3D2584\%26article $\% 3$ D1066\%26mode \%3Dpdf+EFEITO+DO+SOMB REAMENTO+SOBRE+A+PRODUÇÃO+DE+A LFACE+EM+HIDROPONIA $>$, acesso em 20 de abril de 2010.

MAZUCHOESKI, J.Z.; SILVA, E.T.; MACARI JUNIOR, A. Efeito da luminosidade e da adição de nitrogênio no crescimento de plantas de Ilex paraguariensis St. Hil. Revista Árvore. v.31, n.4, 2007.

NEVES, S.M.A.S.; NUNES, M.C.M.; NEVES, R.J. Caracterização das condições climáticas de Cáceres/MT - Brasil, no período de 1971 a 2009: subsídio às atividades agropecuárias e turísticas municipais. Boletim Goiano de Geografia. Goiânia, v.31, n.2, p.55-68, 2011.

PUIATTI, M.; FINGER, F.L. Fatores climáticos. In: PAULO CRF. Olericultura-teoria e prática. 1ed. Rio Branco: Suprema Gráfica e Editora, v.1, p.17-38, 2005.

PURQUERIO, L.F.V.; TIVELLI, S.W. Produção de alface em sistema de plantio direto em função de manejos da cultura de cobertura e da fertilização nitrogenada. In: $3^{\circ}$ CONGRESSO BRASILEIRO DE ASSISTÊNCIA TÉCNICA E EXTENSÃO RURAL, 2006, Campinas. Certificação de produtos agropecuários. Anais.... Piracicaba: FEALQ, 2006, v.3. p.181-185.

PURQUERIO, L.F.V.; TIVELLI, S.W. Manejo do Ambiente em Cultivo Protegido. In: SEMINÁRIO REGIONAL DE AGRICULTURA SUSTENTÁVEL, 2005, Mogi das Cruzes. Anais..., 2005. p.109-121.

QUEIROGA, R.C.F.; BEZERRA NETO, F.; NEGREIROS, M.Z.; OLIVEIRA,A.P.;AZEVEDO, C.M.S.B. Produção de alface em função de cultivares e tipos de tela de sombreamento nas 
condições de Mossoró. Horticultura Brasileira, Brasília, v.19, n.3, p.192-196, 2001.

RYDER, E.J. Crop production science in horticulture: Lettuce, endive and chicory. US department of agriculture, Agricultural Research Service, Salinas, USA. 1999. 208p.

SEMEDO, C.M.B. A intensificação da produção hortícola. 3.ed. Mem Martins: Europan, 1988. 192p.

SGANZERLA, E. Nova agricultura: a fascinante arte de cultivar com os plásticos. Porto Alegre: Plasticultura Gaúcha. 1997. 297p.

SILVA, M.B.; SEABRA JUNIOR, S., RODRIGUES, L.F.O.S.; OLIVEIRA, R.G., NOHAMA, M.T.R.; NUNES, M.C.M.; INAGAKI, A.M., DIAMANTE, M.S. Desempenho de cultivares de couve-chinesa sob telados e campo aberto. Agrarian, n.4, p.91-97, 2011.

SILVA, V.F.; NETO, F.B.; NEGREIROS, M.Z.;
PEDROSA, J.F. Comportamento de cultivares de alface em diferentes espaçamentos sob temperatura e luminosidade elevadas. Horticultura Brasileira, n.18, p.183-187, 2000.

SOUSA, J.W. et al. Alterações do saldo de radiação, temperatura e umidade relativa do ar em ambiente protegido com cobertura de polietileno difusor de luz. Revista Brasileira de Agrometeorologia, Santa Maria, v.13, n.1, p.1-10, 2005.

SZPINIAK, M. Malhas termorefletoras aluminizadas. Disponível em: http://www. polysack.com/index.php?page $\mathrm{id}=24$. Acesso em 18 de maio de 2010.

TELTELA, M.; PELPERA, U.M; ZVIELLO, Y. Telas de sombreamento como proteção contra geadas. 1995. Disponível em: <http://www. polysack.com>. Acesso em: 18 de março de 2010.

WIEN, H.C.L. IN: WIEN, H.C. The physiology of vegetable crops. New York: Cab International. 1997. 